
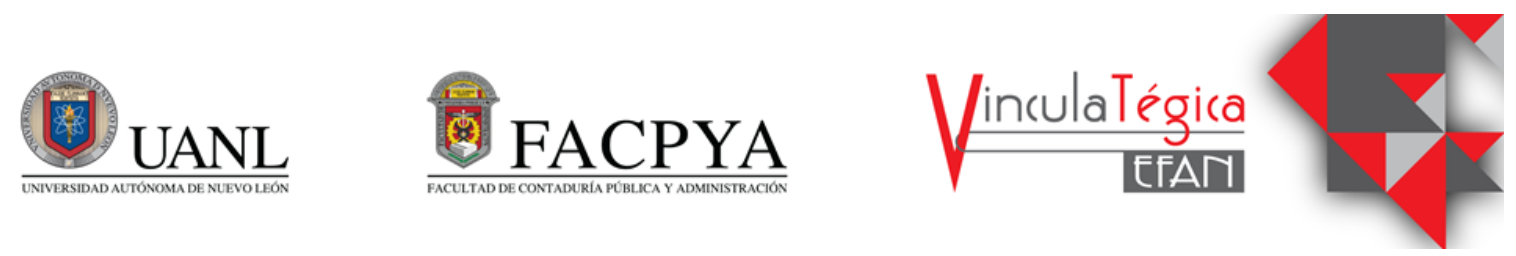

\title{
Los $E$-sports como línea de emprendimiento durante la pandemia por Covid-19
}

\author{
María Guadalupe Arredondo Hidalgo ${ }^{1}$, Diana del Consuelo Caldera González ${ }^{2}$ y Adolfo \\ Ramírez de Sancristóbal ${ }^{3}$ \\ ${ }^{1}$ Universidad de Guanajuato, mg.arredondohidalgo@ugto.mx, Fraccionamiento 1 Col. El Establo 36250 \\ Guanajuato, Gto., México., 4777544247 \\ ${ }^{2}$ Universidad de Guanajuato, dccaldera@ugto.mx, Fraccionamiento 1 Col. El Establo 36250 Guanajuato, \\ Gto., México, 4737325900 \\ ${ }^{3}$ Universidad de Guanajuato, a.ramirezdesancristobal@ugto.mx, Fraccionamiento 1 Col. El Establo 36250 \\ Guanajuato, Gto, México, 4737352900
}

Información del artículo revisado por pares

Fecha de aceptación: junio-2021

Fecha de publicación en línea: diciembre-2021

DOI: https://doi.org/10.29105/vtga7.1-153

\begin{abstract}
Resumen
Abstract

a industria de los deportes electrónicos o ciber deportes se encuentra en un constante crecimiento año con año, adquiriendo cada vez mayor relevancia a una escala internacional. Cada vez más países y empresas ven en esta modalidad una manera de aumentar sus beneficios, y al mismo tiempo, un medio de desarrollo tecnológico y de innovación.

En este trabajo de investigación documental con enfoque descriptivo y diseño no experimental, se analiza la situación actual de los deportes electrónicos, explicando en primera instancia el origen de los videojuegos y el cómo algunos de éstos han podido convertirse en E-sports; luego, se expondrán las cifras a nivel general describiendo lo que ha sucedido en los países más desarrollados en esta industria; y por último, se dará a conocer el panorama que encierra a esta disciplina en México viéndola como una alternativa para la innovación y la creación de empresas, sobre todo en el contexto de la actual pandemia del Covid-19.

The e-sports or cyber sports industry is in constant growth year after year, acquiring more and more relevance on an international scale. More and more countries and companies see in this modality a way to increase their profits, and at the same time, means of technological development and innovation.

In this documentary research work with a descriptive approach and non-experimental design, the current situation of e-sports is analyzed, first explaining the origin of video games and how some of these have been able to become E-sports; then, the figures will be presented at a general level describing what has happened in the most developed countries in this industry; and finally, the panorama of this discipline in Mexico will be presented, seeing it as an alternative for innovation and the creation of companies, especially in the context of the current pandemic of Covid-19.
\end{abstract}

Palabras clave: E-sports, innovación, sofisticación empresarial.

Keywords: E-sports, innovation, business sophistication.

JEL: L67, L82, O15. 


\section{INTRODUCCIÓN}

La industria de los ciber deportes, en México, ha llegado a ser una oportunidad de ingresos para cientos de jóvenes en el periodo de pandemia, ya que, en la actualidad, se entiende que el hecho de pasar tiempo "jugando un juego", ya no es más una actividad de ocio.

El objetivo del trabajo de investigación es analizar el impacto económico de la industria de los E-sports a partir de la sofisticación de las empresas que han desarrollado estos modelos de negocios. La industria de los videojuegos, a raíz de la cuarentena ocasionada por el virus del SARS-CoV-2, ha sido una de las industrias que, lejos de verse afectada, ha incrementado considerablemente sus ganancias a nivel mundial. En esta aproximación, se analiza la industria de los $E$ sports en otros países para determinar qué factores podrían implementarse en México con el fin de mejorar la industria interna.

La industria de los videojuegos, a pesar del poco tiempo de vida que lleva (aproximadamente 50 años), es una de las industrias que más beneficios económicos

Figura 1. Distribución porcentual de las ventas de videojuegos, por regiones en el mundo.

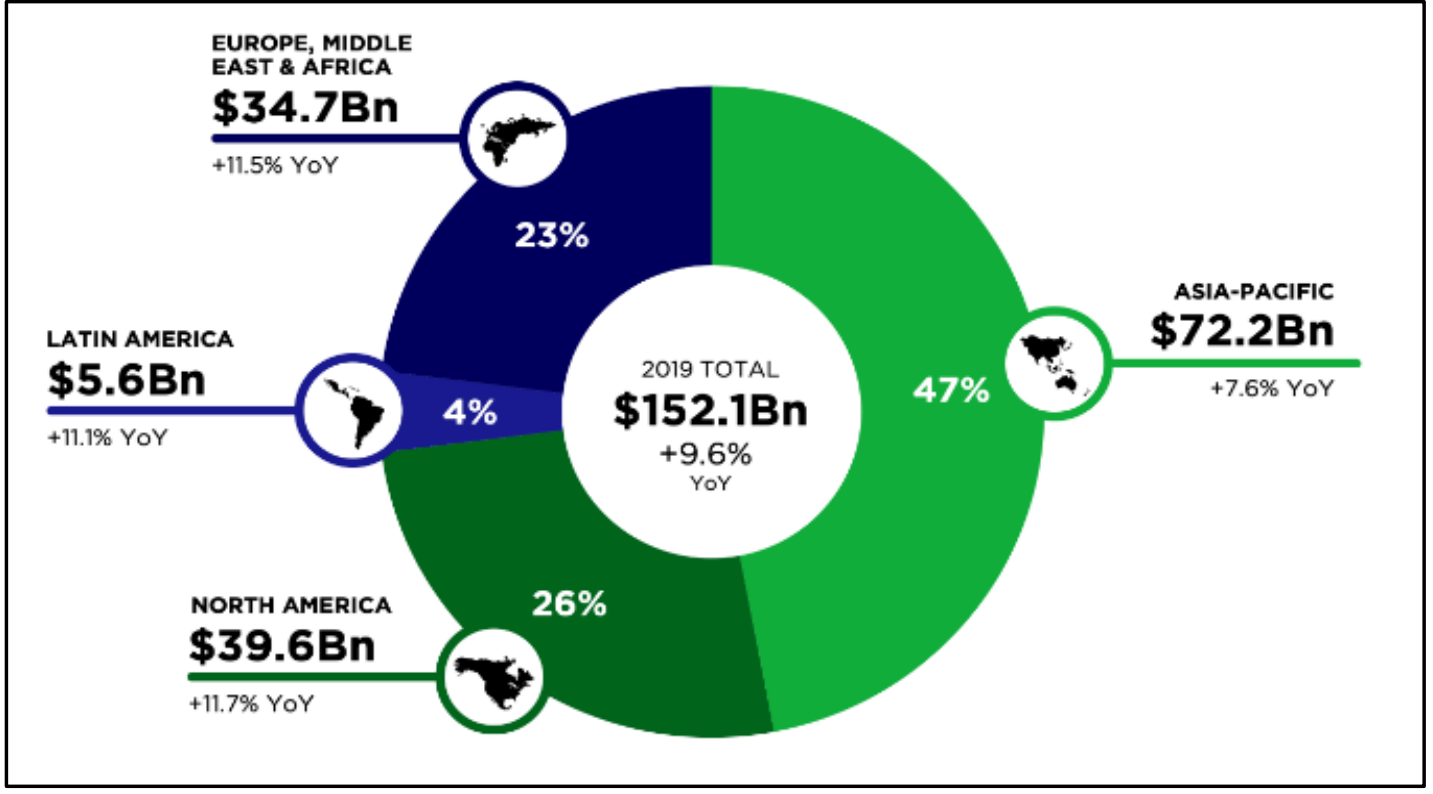

NOTA: YoY: año con año, con cifras en billones de dólares.

Fuente: extraído de Newzoo, 2019 percibe año con año, incluso superando a los ingresos de las industrias de la música y del cine, juntas. Según estimaciones de Newzoo, agencia de estadística más importante del sector de los videojuegos, en 2019, esta industria alcanzó una facturación a nivel mundial de 152 mil millones de dólares, lo que representó un crecimiento de $9.6 \%$ respecto al año anterior. Casi la mitad de esta cifra (un 47.4\%) viene de la región AsiaPacífico, principalmente de los mercados chinos y japoneses (Wijman, 2019).

La región de Latinoamérica en el año 2019, fue la cuarta región que más ingresos generó en la industria, principalmente por la participación de México y Brasil, que produjeron un total de 5,600 millones de dólares, lo que representó un crecimiento del $11.1 \%$ respecto al año anterior. Este crecimiento, aunado a la cantidad de jugadores que se sumaron, convierte a la región latinoamericana en la de mayor crecimiento del mundo. Además, México es el líder actual de la región y es considerado como el doceavo lugar a nivel mundial (Zapién, 2019). 
A la industria de los E-sports (más adelante se explica la diferencia entre $E$ sports y los videojuegos), en 2017, ingresaron un total de 950 millones de dólares (Guiñón, 2017), lo que representa menos del $1 \%$ del total de la industria de los videojuegos. Esta cifra, como se puede ver, aunque es sustancialmente menor, sigue siendo una suma significativa, tres cuartas partes de estos ingresos son obtenidos gracias a los derechos de retransmisión y a los patrocinios. Cabe remarcar que en esta cantidad se dejaron fuera el cálculo de los premios, los salarios de los jugadores, las contribuciones de los fans a los premios, los ingresos de las apuestas relacionadas con los E-sports y las inversiones que reciben los clubes de deportes electrónicos (Cristòfol et al., 2020).

En 2021, pese a las enormes incógnitas que ha traído consigo la pandemia covid-19, y aun cuando muchos sectores se han visto en peligro debido a las interrupciones laborales a causa de lo mismo, la industria de los Esports ha sido una de las pocas que ha logrado beneficiarse de esto. Diversas agencias de noticias atribuyen este crecimiento como un efecto de la cuarentena a la que tuvimos que someternos, es decir, que los deportes electrónicos han crecido gracias a que las personas se vieron obligadas a realizar actividades desde sus casas; sin embargo, se dice, que al terminar el encierro esta industria volverá a sus cifras normales de usuarios (Galván, 2020).

\section{MARCO TEÓRICO}

\section{La Industria de los videojuegos}

De acuerdo con la Real Academia Española, la palabra videojuego se puede definir como: "juego electrónico que se visualiza en una pantalla", o también: "dispositivo electrónico que permite, mediante mandos apropiados, simular juegos en las pantallas de un televisor, una computadora $\mathrm{u}$ otro dispositivo electrónico".

$\mathrm{Al}$ igual que con cualquier otra industria perteneciente al entretenimiento, el origen o inicio de los videojuegos, no está del todo claro, sin embargo, se ha llegado a un "acuerdo" no escrito en el cual se ha determinado que el punto de partida se encuentra en el año 1952, con la invención del juego Nought and Crosses, también llamado OXO; éste, fue desarrollado por Alexander S. Douglas como parte de su trabajo doctoral en la Universidad de Cambridge. Posteriormente, en 1958, el físico William Higginbotham, desarrolló el juego Tennis for two, el cual, ayudándose de un programa para calcular trayectorias y un oscilatorio, simulaba un juego de tenis (Belli y López Raventós, 2008).

Cuatro años más tarde, en 1962, Steve Russell, estudiante del Instituto de Tecnología de Massachusetts (MIT), creó el primer juego para computadora, bautizándolo como Spacewar. Este juego fue un hito, ya que se separó de la era análoga y dio paso a la era digital. Sin embargo, pese a la popularidad que ganó, tanto dentro como fuera de dicha universidad, su comercialización no pudo ser posible, ya que era jugado en computadoras sumamente costosas, las cuales, en ese momento, no eran de fácil acceso al público (Kowert \& Quandt, 2016). Es en el año 1971, cuando Nolan Bushnell, estudiante de la Universidad de Oxford, desarrolla una versión similar de Spacewar, pero lo que la hacía distinta, es que ésta podía ser jugada en una máquina que servía específicamente para esto y cuya elaboración era más económica que la de una computadora de esa fecha. (Belli y López Raventós, 2008). Este hecho dio paso a dos de los sucesos más relevantes en la historia de los videojuegos: a las "Arcades" (actualmente extintas); y a la Atari, la primera consola conocida.

Atari, sirvió como precursor de muchas otras consolas que, al igual que ella, comenzaron a captar la atención del público en muy poco tiempo. Sin embargo, en 1983, este auge se vio opacado por lo que hoy se conoce como la crisis del videojuego. Este acontecimiento afectó especialmente a Estados Unidos y a Canadá, quienes en aquel entonces eran los principales - por no decir únicos - desarrolladores de videojuegos; esto causó que empresas en otras partes del mundo vieran una oportunidad de 
introducirse en esta industria. Fue así como en Japón, en ese mismo año, Nintendo lanzó al mercado la consola Famicom (conocida en occidente como Nintendo Entertainment System [NES]) siendo todo un éxito de ventas y marcando toda una generación de nuevas consolas domésticas. (Belli y López Raventós, 2008).

En 1985, cuando la crisis del videojuego culminó, la mayoría de las empresas estadounidenses ya no tenían la capacidad para poder competir con la NES de Nintendo, por lo que decidieron "adoptarla", es decir, que comenzaron a desarrollar juegos que podían ser jugados en esta consola.

A finales de los 80s, principios de los 90s, con el salto técnico que significó la arquitectura de 16 bits, las empresas de videojuegos no demoraron en implementar esta nueva tecnología en el desarrollo de sus lanzamientos, consiguiendo así los primeros entornos tridimensionales. Posteriormente, en 1993, con la llegada de la arquitectura de 32 y 64 bits, surgieron las primeras consolas portátiles, las cuales permitían que el usuario pudiera entretenerse sin la necesidad de quedarse estático en un mismo lugar. Cinco años más tarde, en 1998, con el desarrollo de la arquitectura de 128 bits, la fabricación de videojuegos dio un salto muy importante, ya que esta nueva tecnología permitía crear entornos de jugabilidad más dinámicos y con mecánicas más fluidas, lo que impulsó a que más personas se adentraran en este mundo (Banks, 2017).

Desde 2005 hasta la actualidad, la fabricación de consolas de videojuegos se ha llegado a considerar como un oligopolio, debido a que existen sólo tres grandes competidoras: Sony (PlayStation), Microsoft (Xbox) y Nintendo. Pero, cuando se hace referencia al desarrollo meramente de videojuegos, existen una infinidad de empresas que aún se dedican a esto.

No obstante, las consolas, no son el único medio que existe hoy día para jugar videojuegos, ya que también podemos hacer uso de dispositivos móviles (smartphones y tabletas), de equipos de cómputo (laptops y computadoras de escritorio) y de otras plataformas para juegos más casuales (Facebook o páginas de internet).

\subsection{Origen de los E-sports}

De acuerdo con Riquelme (2020), la primera vez que se usó el término E-sports fue a finales de la década de los 90s y fue empleado por el periodista británico Matt Bettington, quien comparaba los deportes electrónicos con los deportes tradicionales. Sin embargo, aunque este término es de creación reciente, los torneos de esta índole datan de años atrás; distintas fuentes coinciden en que el primer torneo de E-sports se llevó a cabo en 1972 en la Universidad de Stanford, en donde un grupo de cinco estudiantes compitieron en el juego Spacewar. Luego, en 1980, la empresa Atari convocó a un torneo de Space Invaders el cual convocó a 10,000 personas, lo que lo convierte en el primer evento masivo de este tipo. (Riquelme, 2020). En 2008, aprovechando que el ambiente competitivo de los E-sports se estaba volviendo popular y estaba consiguiendo una gran audiencia, se fundó la Federación Internacional de E-sports (IeSF), la cual contribuyó enormemente a que los deportes electrónicos sean lo que son hoy, desde el establecimiento de reglas internacionales, hasta la aplicación de estándares con el fin de mantener la integridad de los juegos. Al principio, esta federación comenzó con nueve países integrantes y, en la actualidad, cuenta con ochenta y ocho miembros (Young, Nauright \& Suveatwatanakul, 2020).

Aunque la importancia de los E-sports es un hecho medible y reconocido por diversas asociaciones de deportes, aún persiste el debate entre aceptarlo o no como un deporte real. Parry (2018) argumenta que existen seis criterios principales que todo deporte debe tener: 1) ser practicado por humanos, 2) ser físico, 3) requerir de habilidad, 4) deben existir concursos, 5) debe tener reglas que lo regulen, y 6) ser institucionalizado. Sin embargo, de aceptar estos criterios, muchos de los deportes actuales "correrían con la misma suerte" que los deportes electrónicos. 


\subsection{Diferencia entre Videojuegos y $E$ - sports}

Para aclarar las diferencias que existen entre estas dos industrias, podemos partir de una premisa muy sencilla: "Todos los E-sports son videojuegos, pero no todos los videojuegos son E-sports".

De acuerdo con Gimeno (2019), los deportes electrónicos deben cumplir con ciertos requisitos: todos los jugadores deben estar en igualdad de condiciones, esto quiere decir que no debe ser un juego Pay to Win o traducido al español, pagar para ganar, en donde los jugadores que inviertan más dinero son los que tienen una mayor posibilidad de llevarse la victoria. Por tanto, lo que realmente determina el triunfo es la habilidad de los jugadores. Además, el juego debe tener un ambiente competitivo, en donde cientos o miles de jugadores se reúnan cada determinado tiempo con el afán de rivalizar entre sí. Estos enfrentamientos pueden darse de manera presencial $\mathrm{u}$ online. Otro factor importante es que debe mantenerse con constantes actualizaciones, esto con el fin de arreglar problemas de desequilibrios que surjan, evitando así que se vuelva desigual. Por último y el punto más importante es el hecho de que debe tener una liga competitiva, seria y regulada, en donde distintos equipos puedan competir entre sí para ganar premios. En estas ligas, deben existir patrocinadores y/o empresas que las sostengan, al mismo tiempo que hacen promoción en medios convencionales de publicidad.

\subsection{E-sports}

Hasta la fecha, la palabra E-sports aún no cuenta con una definición aceptada por la mayoría, aunque, de acuerdo con lo que dice Del Río González (2018) "se le considera como la práctica competitiva, ya sea contra otros jugadores o contra variables como el tiempo, de los videojuegos actuales".
Otra definición que existe acerca de esta práctica fue dada por el fundador de la Liga de Videojuegos Profesional, Sergi Mesonero (Citado en Chanson, 2017):

Los E-sports son competiciones de videojuegos estructuradas, ni más ni menos. No creo que haya que complicarse demasiado. En esta definición caben tanto las competiciones amateurs como las competiciones profesionales, que están dirigidas más hacia el espectáculo y a los espectadores. Hay intentos de definir a los E-sports desde una perspectiva más cerrada incluyendo sólo las competiciones profesionales, pero para mí, siempre que las amateurs tengan una estructura y un espíritu deportivo detrás, se deben incluir también (Chanson, 2017, p.31).

\subsection{Impacto económico de los $E$-sports}

$\mathrm{Si}$ bien un videojuego debe tener cierta estructura y reglas que le permitan ser considerado un e-sport, esto no se limita al dispositivo donde es jugado, esto quiere decir que, aunque la mayoría de los deportes electrónicos son jugados en equipos de cómputo, también existen casos en donde pueden llevarse a cabo en consolas y en dispositivos móviles. La figura 2 indica las ganancias generadas por esta industria.

Año con año, los deportes electrónicos aumentan su nivel y profesionalización y con ello, logran atraer a grandes marcas que quieren publicitarse a través de ellas. De acuerdo con la agencia de marketing Antevenio (2019), el mercado objetivo al que van dirigido los E-sports puede delimitarse de manera sencilla como: adultos jóvenes entre los 21 y 35 años; además con frecuencia se piensa que este deporte está dirigido hacia el público masculino (mayormente sí), pero, desde hace unos años, la participación de mujeres dentro de éstos ha ido en aumento. 
Figura 2. Distribución porcentual de las ganancias de los E-sports

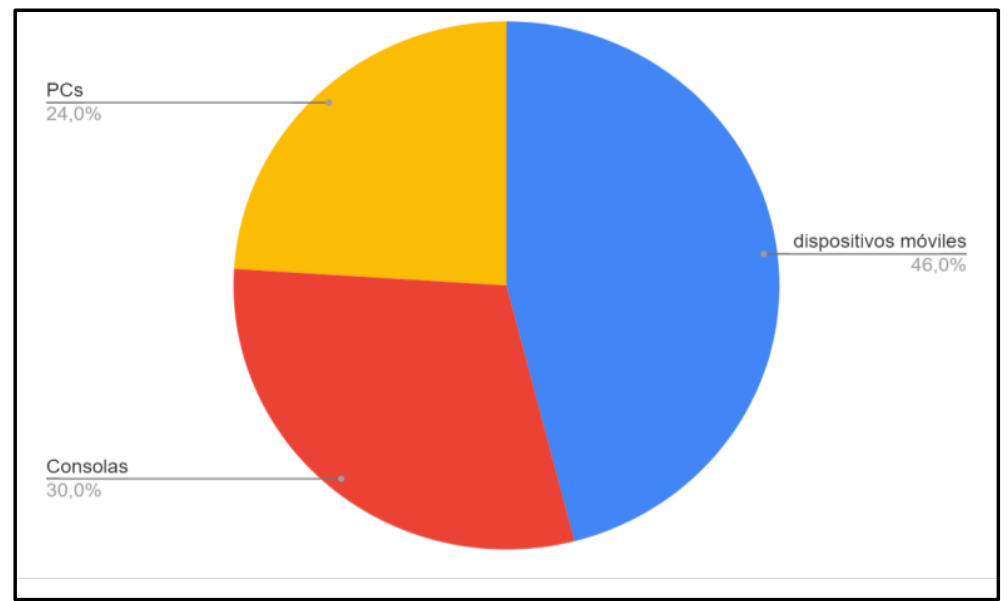

Fuente: Elaboración propia con datos de Newzoo, 2019.

$\mathrm{Al}$ igual que en el fútbol o en la Fórmula 1, las marcas que deseen ingresar en esta industria pueden hacerlo por dos caminos: patrocinando equipos conocidos o publicitándose durante un evento, torneo o competencia.

Por lo general, hasta hace unos años, las marcas que aprovechaban esta plataforma de los deportes electrónicos eran marcas que se podían considerar afines a la industria, es decir, empresas de tecnología, de videojuegos $\mathrm{o}$, tal vez, de bebidas energéticas; sin embargo, actualmente, hay registros que

Figura 3. Distribución porcentual de las actividades que más ingresos generan en los E-sports

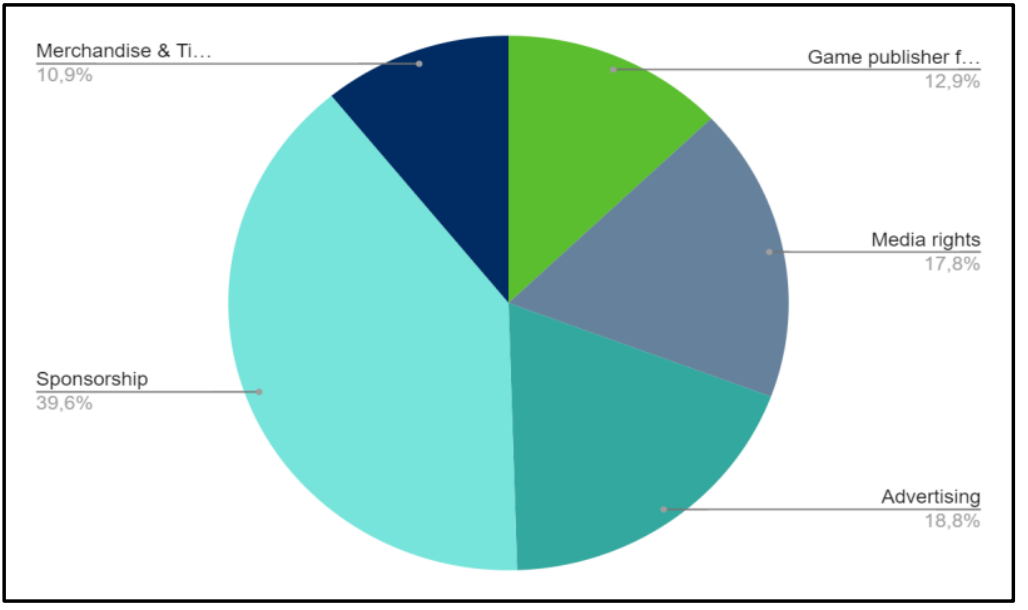

Fuente: Elaboración propia con datos de Newzoo, 2019.

\subsection{Premios}

Este factor ha sido el que más ha motivado o indican que empresas como Nike, Domino's, Mercedes-Benz o hasta Gucci, han decidido usar este medio.

Según datos de Newzoo, de los casi mil millones de dólares que generaron los $E$ sports en el 2018, un 40\% provienen de los patrocinadores y $19 \%$ de la publicidad, es decir, que más de la mitad de lo que se generó viene únicamente de dos fuentes. También, cabe recalcar que ambas fuentes tuvieron incrementos con respecto al año anterior, siendo de $53.2 \%$ y $23.8 \%$ respectivamente.

impulsado a la mayoría de los jugadores profesionales para adentrarse en esta industria, ya que, aunque al principio haya 
comenzado como un pasatiempo, ven que existe la oportunidad de poder vivir de ello. En la escena competitiva se pueden encontrar casos de jóvenes (principalmente en las regiones asiáticas y europeas) que, después de entrenar durante cierto periodo de tiempo, han convertido su afán de jugar videojuegos en algo que les genera un ingreso; no obstante, retomando el parecido que existe con el fútbol, no todos los que juegan a este deporte pueden convertirse en profesionales.

Uno de los años más prolíficos en la industria de los deportes electrónicos fue 2019; ya que, si bien la cantidad de torneos o competencias no se alejó del común, los premios que se otorgaron sí fueron mucho más sobresalientes. Según datos de Maeso (2020), contando únicamente los premios que se dieron en los diez torneos de E-sports más importantes, se juntó una bolsa de más de 184 millones de dólares.

\subsection{Apuestas}

El mundo de las apuestas es muy difícil de contabilizar, esto debido a la gran cantidad de páginas que existen para hacerlo (tanto oficiales como no oficiales), sin embargo, hay agencias que, con el fin de regular dicha actividad, tienen la labor de generar estimaciones de cuánto dinero mueven. Mateo (2019), con datos de la firma Eilers \& Krejcik Gaming, estimó que la industria moverá una cifra de 13,000 millones de dólares, esto contando todas las formas de betting: apuestas con dinero real, con artículos/skins de los juegos y criptomonedas. Para darnos una idea de cuán considerable es esta cifra, vale la pena compararla con la cantidad que la BBC estimó para la industria del fútbol en 2013: entre 49,000 y 70,000 millones de dólares. En este factor de las apuestas, los títulos de E-sports que más dinero mueven son: League of Legends, con un $38 \%$ de las apuestas realizadas; CS: GO, con 29\%; y Dota 2, con 18\%; seguidos de otros.

\subsection{Merchandising}

El merchandising o merchandise, es una de las principales fuentes de ingreso que tiene un equipo profesional de E-sports, quienes, al igual que en los deportes tradicionales, deben mantenerse en constante cambio para seguir atrayendo la atención de sus fanáticos.

Para equipos como G2 o FNATIC, dos de los equipos más grandes de League of Legends en occidente, la inversión en ropa o accesorios ha traído sus beneficios, no obstante, para muchos clubes pequeños esto puede convertirse en algo perjudicial debido a que no cuentan con una base sólida de entusiastas, es por eso por lo que, la mayoría, optan por fabricar un número limitado de prendas.

Otro dato, es el hecho de que muchos clubes de otras disciplinas - principalmente fútbol - han empezado a incursionar en el mundo de los E-sports, por lo que se ha vuelto común ver equipos como Paris SaintGermain (Fútbol), Raptors (NBA) o inclusive el Club Deportivo Guadalajara (Fútbol), jugando torneos de deportes electrónicos. Al hacer esto, ellos ya cuentan con un soporte de fanáticos que los siguen independientemente de la actividad que hagan, esto vuelve más sencilla la labor de venta del merchandise de su nuevo equipo de e-sport. En 2018, el merchandising representó un $10.9 \%$ del total de los ingresos generados, lo que se traduce en poco más de 95 millones de dólares (Newzoo, 2019).

\subsection{Monetización en plataformas de video}

No cabe duda de que la internet ha sido la principal herramienta que ha permitido que los E-sports hayan logrado la masividad que hoy día los caracteriza, pero hasta hace unos años, si alguien quería ver una competencia o un torneo de un deporte electrónico, debía buscar exhaustivamente en la web, a veces sin obtener resultados. Sin embargo, en 2005, con la invención de YouTube, esto cambió. La plataforma se ha convertido en el punto de reunión para millones de videos, entre ellos, los relativos a la industria de los E-sports, por lo que, actualmente es mucho más fácil ver la transmisión o retransmisión de los deportes electrónicos. De acuerdo con estimaciones de Newzoo (2019), la cantidad de espectadores de E-sports ascenderá a 557 millones de 
usuarios para 2021, lo que se traduce en un mercado más grande y por tanto más atractivo para las marcas que deseen publicitarse.

Actualmente existen tres grandes plataformas de streaming, cada una brindando algo diferente de la otra, y, las cuales representan más del $90 \%$ del mercado. En primer lugar, con un $61 \%$ del total, se encuentra Twitch. Esta plataforma ganó relevancia en 2014 cuando la empresa Amazon decidió comprarla. Desde su adquisición, la página se ha encontrado en constantes cambios, lo que la mantiene siempre innovadora y moderna, además frecuentemente genera tratos con empresas desarrolladoras de videojuegos y con streamers famosos, para tener exclusividad dentro de su canal. La plataforma es de acceso gratuito, cuenta con una suscripción mensual que brinda recompensas en una gran cantidad de juegos, lo que la convierte en la única de las tres plataformas que puede hacer esto. Esta plataforma recibe un promedio diario de dos millones de espectadores (Twitch Tracker, 2020).

La segunda plataforma más importante es YouTube Gaming; es un apartado dentro del mismo YouTube en donde los creadores de contenido pueden hacer directos con el fin de llegar a una audiencia. Si bien YouTube es conocida por ser una página de videos, desde hace unos años también se presenta como una opción viable al momento de hacer streaming. Su cuota de mercado asciende al $27.9 \%$ del total. Lo interesante de ésta es que permite a los creadores de contenido una exposición más grande ya que su target no se ve limitado a la comunidad gamer. Otro factor importante, es el hecho de que Blizzard (una de las desarrolladoras de videojuegos más importante de la industria) anunció a principios de este año que iba a transferirse a YouTube Gaming, con esto, hizo que una gran parte de sus seguidores migrara hacia esta plataforma.

En tercera posición, con un $8.5 \%$ del mercado total, se encuentra Facebook Gaming, al igual que YouTube Gaming, es el apartado que permite a creadores de contenido generar sus streams dentro de Facebook. Cabe recalcar que, aunque $8.5 \%$ parezca una cantidad muy pequeña de porcentaje en comparación a sus dos competidoras, esta plataforma es la que ha mostrado un mayor crecimiento año con año. El punto que la distingue y por lo que ha empezado a llamar la atención dentro de la comunidad de streamers, es que brinda una mayor cantidad de opciones para generar ingresos en comparación a sus rivales, además de que el proceso es menos burocrático.

\subsection{E-sports de mayor crecimiento en la última década}

Así como sucede en cualquier otra industria, la industria de los E-sports cuenta con juegos que son los que más atraen la atención de los espectadores. Para poder entender la relevancia que cada uno de ellos tiene, se tomarán en cuenta los siguientes factores: premios de torneos y competencias, presencia en plataformas de streaming y número (aproximado) de fanáticos a nivel global.

Es importante aclarar que juegos como Fortnite o PUBG, a pesar de que son de los deportes electrónicos que mayores premios otorgan en sus torneos, no entran en esta categoría ya que no cuentan con una gran presencia fuera del ámbito competitivo.

\subsection{Dota 2}

Antes de que este juego saliera al público, la dinámica que operaban los deportes electrónicos de ese momento era demasiado monótona por lo que la audiencia era considerablemente más reducida que la que existe actualmente. Desde su lanzamiento en 2013, Dota 2 ha sido el e-sport que mayor relevancia ha tenido tanto en la escena profesional, como en la escena amateur; esto lo logró, en gran medida, gracias a su estrategia de torneo, en donde convocó a los mejores jugadores del juego y los hizo competir entre sí, y en donde el ganador se llevaría un premio de un millón de dólares, cifra que año con año ha ido en aumento. En 2019, la cifra del premio alcanzó una suma 
récord, siendo de 34 millones de dólares.

Pese a que este deporte es considerado el rey de los E-sports, tiene un problema muy grande y es el hecho de que su desarrolladora (Valve) pocas veces da cabida a nuevos jugadores o inclusive a nuevos clubes, lo que desalienta a quienes tratan de adentrarse a este juego (Academia E-sports, s.f.).

\section{Counter Strike: Global Offensive}

Counter Strike es uno de los E-sports que más tiempo lleva en la escena profesional; su historia se remonta al año 2002 cuando el panorama competitivo apenas estaba instalándose. Gracias a su longevidad, ha generado una de las audiencias más grandes de la industria, misma que se mantiene fiel al juego. En 2019, fue el tercer e-sport que más premios entregó. Debido a la fama que ha logrado y a la cantidad de fanáticos que tiene, es uno de los deportes electrónicos con más torneos y competencias en el año, siendo uno de los principales eventos en la competencia World Electronic E-sports Game. Además, algo que ha incrementado su popularidad es que son de los pocos deportes que cuentan con una liga femenil, la cual desde hace unos años ha empezado a tomar relevancia en la comunidad gamer.

\section{League of Legends}

Creado en el año 2009, League of Legends es uno de los casos más interesantes de la industria, ya que, pese a no ofrecer premios con cantidades tan cuantiosas como su competencia, su nombre ha permeado en distintos países alrededor del mundo. Actualmente, este e-sport se encuentra en el rango número uno de espectadores en la plataforma de Twitch, con un promedio de 150 mil viewers diarios. (Twitch Tracker, 2020). Parte de su éxito se debe a la estructura que han manejado al momento de las competencias y torneos, ya que han creado ligas en distintas regiones del mundo, por ejemplo: China, Corea del Sur, Latinoamérica, Estados Unidos, Brasil, etc. Esta división por regiones permite que equipos pequeños puedan aspirar a competir profesionalmente sin necesidad de invertir cantidades numerosas de dinero. Además, si un equipo logra ganar su liga, éste tiene acceso directo al mundial, lo que deriva en mejores premios para el club.

Como último dato, la empresa desarrolladora de este deporte electrónico, Riot Games, fue adquirida por la compañía multinacional Tencent en 2015. Es una de las empresas chinas más importantes de aquel país, y cuyo giro se centra en la publicidad y en proveer productos y servicios de internet. Tan sólo en 2019, y por conceptos de venta y distribución de videojuegos, esta empresa generó un total de 5,225 millones de dólares (Newzoo, 2019).

Tabla 1. Compañías de videojuegos que más ingresos generaron durante 2019

\begin{tabular}{ccc}
\hline Posición & Compañía & Ganancias en millones de dólares \\
\hline 1 & Tencent & 5,225 \\
2 & Sony & 3,879 \\
3 & Apple & 2,887 \\
4 & Microsoft & 2,831 \\
5 & Nintendo & 2,886 \\
\hline \multicolumn{2}{c}{ Fuente: Newzoo, 2019. }
\end{tabular}

\section{FIFA}

Aunque este deporte electrónico no es tan grande como los otros tres, vale la pena hablar de él ya que se trata del único e-sport que no se juega en computadoras, sino en consolas. A diferencia de los tres primeros, este juego ya tiene un periodo largo de 
tiempo en el mercado, haciendo su primera aparición en el año 1993 para la consola Sega Genesis y debutando como e-sport en el año 2000 (Meristation, 2020).

El factor que más ha jugado a su favor es el hecho de que tiene al deporte tradicional más influyente: el soccer. Con esto, el juego de FIFA no tiene sólo fanáticos de los deportes electrónicos dentro de su audiencia, sino también a los seguidores de este deporte. En los últimos años, la relación entre el fútbol tradicional y el fútbol electrónico ha mejorado enormemente, a tal grado que equipos y jugadores profesionales del deporte clásico han decidido crear una ramificación enfocada al deporte digital; algunos de los casos más sonados han sido: Paris SaintGermain (Francia), Club Deportivo Guadalajara (México), Real Madrid CF (España), FC Schalke 04 (Alemania), o inclusive jugadores como Zlatan Ibrahimovic (Romero, 2019).

Rosas (2020) menciona que FIFA 21 (el juego más reciente de la franquicia), se consolidó como el videojuego más vendido del mes de octubre del presente año, logro que parece extraño ya que en ninguna de sus anteriores entregas lo había conseguido, este hecho se debió principalmente al buen recibimiento que tuvo este título en el mercado japonés.

\section{Caso Región Asia-Pacífico}

Actualmente, la región Asia-Pacífico es considerada la región económica más importante del planeta; según datos del portal de noticias chino, Xinhua News (2020), este territorio representa el $38 \%$ de la población mundial, el $61 \%$ del PIB mundial y el $47 \%$ del comercio mundial. Países como China, Corea del Sur o Japón, son reconocidos por sus avances dentro del ámbito tecnológico, pero además, por tener tasas de pobreza muy bajas o tasas de población en clase media muy altas. Esto último, permite que sus habitantes puedan costear sus gastos indispensables, como comida, agua, luz o vivienda, y aun así contar con efectivo sobrante, pudiendo así, gastarlo en bienes o servicios triviales, como viajes, carros o boletos de cine, o si lo vemos desde el punto de vista de los E-sports, pueden comprar dispositivos móviles, consolas de videojuegos o equipos de cómputo modernos.

\section{China}

Los videojuegos se han convertido en una actividad muy popular dentro de la cultura china. De acuerdo con datos de Newzoo (2019), se espera que esta industria genere más de 40 mil millones de dólares para finales de 2020. Estas cifras se deben, en gran medida, a dos factores: 1) al porcentaje de personas que tienen acceso a internet, de aproximadamente 900 millones, lo que convierte a China en el país con más internautas en el mundo, y 2) los avances tecnológicos, lo que consigue que industrias como la de los videojuegos decidan establecerse en este país.

Los E-sports para PC que más se juegan en este gigante asiático son: League of Legends, Dota 2, CrossFire, Clash Royale, Arena of Valor y Honor of Kings. La King Pro-League (de Arena of Valor) o la final de 2018 de la mid-season Invitational de League of Legends, fueron vistas por 15 millones y 126 millones de espectadores respectivamente. Sin embargo, el mercado más grande de deportes electrónicos de este país recae en los dispositivos móviles, ya que más del $95 \%$ de los usuarios de internet utilizan sus smartphones para conectarse.

Otro punto para destacar es la actual profesionalización que se le da a esta práctica, desde entrenadores hasta estadios específicamente para E-sports, es lo que ha logrado que China sea visto como uno de los países más importantes dentro de este rubro. En 2019, este país reconoció a los E-sports como una actividad profesional mediante un organismo llamado Ministerio de Recursos Humanos y Seguridad Social, legalizando así títulos como "profesional de los E-sports" u "operador de E-sports", lo que brindaría a los jugadores derechos laborales como visas de trabajo (Garza, 2019). No obstante, esta profesionalización también ha traído una competitividad enorme entre los jugadores, lo que causa que muchos de ellos jamás puedan 
debutar en la escena profesional.

\section{Corea del Sur}

Este mercado, es considerado como el más importante para la industria de los videojuegos. En 1963, al llegar Park Chung Lee al poder, éste se dio cuenta que la economía del país se encontraba estancada, por lo que, valiéndose de su poder y autoritarismo, obligó a las empresas más productivas de ese tiempo a cambiar su giro comercial a uno que impulsase el desarrollo tecnológico de la región, creando así los famosos Chaebol. Este impulso que se le dio a la tecnología logró que, en menos de 30 años, Corea se levantará como una potencia económica. En los años 90s, habiendo conseguido una industria tecnológica comparable incluso a la de su vecino Japón, empezaron a surgir startups cuyo negocio era la apertura de ciber cafés, lugares en donde se pudiera convivir con amigos al mismo tiempo que puedes jugar en internet. Este modelo de negocio ganó tanta popularidad que, en sólo tres años, de 1997 a 2000, la apertura de establecimientos con esa temática se multiplicó por 200 en todo el país (García Callealta, 2016), impulsando así el comienzo del actual imperio coreano de los E-sports. En la actualidad, Corea tiene el cuarto lugar en el ranking de países que más ganancias generarán para la industria de los videojuegos en 2020, tan sólo por debajo de China, Estados Unidos y Japón; lo impresionante de este caso es que la población coreana es mucho menor en comparación a la de los tres países que están por debajo de ella (Alemania, Reino Unido y Francia). La tabla 2 explica los datos anteriormente expuestos.

Tabla 2. Países con mayores ganancias por videojuegos

\begin{tabular}{clllll} 
Lugar & País & Región & $\begin{array}{l}\text { Población } \\
\text { (millones de } \\
\text { habitantes) }\end{array}$ & $\begin{array}{l}\text { Población con interntet (millones de } \\
\text { habitantes) }\end{array}$ & $\begin{array}{l}\text { Ganancias } \\
\text { (Millones de } \\
\text { dólares) }\end{array}$ \\
\hline 1 & China & Asia-Pacífico & 1,439 & 907.5 & 40,854 \\
2 & EE.UU & Norteamérica & 331 & 284.9 & 36,921 \\
3 & Japón & Asia-Pacífico & 126.5 & 101.5 & 18,683 \\
4 & Corea del & Asia-Pacífico & 51.3 & 48.2 & 6,564 \\
& Sur & & & 75.5 & 5,965 \\
5 & Alemania & Europa & 83.8 & 61.8 & 5,511 \\
6 & Reino Unido & Europa & 67.9 & 58.2 & 3,987 \\
7 & Francia & Europa & 65.3 & 5.2 & \\
\hline
\end{tabular}

Fuente: elaboración propia con datos de Newzoo, 2019.

Al igual que China, este país cuenta con distintas ligas en varios deportes electrónicos, siendo la más conocida la League of Legends Champions Korea (o LCK) de League of Legends. La profesionalización que han dado a esta práctica es un punto característico de este mercado, a tal grado que sus deportistas de E-sports suelen estar mejor pagados que sus atletas de deportes tradicionales. Además, en 2018, Riot Games (la empresa desarrolladora de League of Legends) inauguró el LOL Park, una infraestructura que hará de estadio para la LCK, lo que causó un impulso aún mayor para la industria de los videojuegos de este país (Pérez, 2018).

\section{Otros países de la región Asia-Pacífico}

Otros países que también han empezado a generar sus propias ligas son: Hong Kong, Taiwán, Malasia, Indonesia e inclusive Australia. Sin embargo, para muchas de las empresas desarrolladoras y también para las empresas de patrocinios, sigue sin ser muy atractiva la idea de invertir en ellas. Aunque, si algo puede decirse, es cuestión de tiempo para que estos mercados sean igual de competitivos y profesionales que China o Corea del Sur.

\section{Región Europa}

Aunque la región europea, representada principalmente por Alemania y España, no es 
la zona que más ingresos genera para la industria de los videojuegos en el hemisferio occidental, es para muchos la única región que puede competir realmente con el dominio asiático. Según datos de Newzoo (2019), la zona conformada por Europa, Medio Oriente y África, representa el $23 \%$ del total de las ventas, lo que equivale a más de $34 \mathrm{mil}$ millones de dólares. Las ligas que se han ido formando dentro de Europa, desde hace ya varios años, son las más importantes de este lado del mundo, ya que, al igual que los clubes orientales, han creado una infraestructura muy sólida alrededor de sus equipos.

Algo que ha caracterizado a esta región, es que sus clubes deportivos más importantes no pertenecen a un país en específico. Los dos casos más conocidos son: G2 y FNATIC; estos dos clubes participan en distintos deportes y agrupan a jugadores de Dinamarca, Suecia, España, Alemania, Eslovenia, Bélgica, etc.

\section{Alemania}

La historia de los videojuegos dentro del mercado alemán es muy reciente, y se remonta a la década de los 90s. Tras la caída del muro de Berlín, y con una Alemania dividida en dos mundos diferentes, era notoria la diferencia que había entre ambos; mientras los juegos de computadora y los videojuegos eran inaccesibles para la mayoría de las personas en el lado Este, del otro lado esta industria empezaba a gestarse como un medio popular (Lange y Liebe, 2015).

Reymann-Scheneider (2018) afirma que Alemania es el quinto mercado más importante en el mundo y tienen una mayor inclinación hacia los juegos de estrategia, tanto si se compite de forma individual como si se hace en equipo, siendo éste el género que más público tiene; es aquí donde podemos ubicar títulos como Dota 2, League of Legends o Smite.

Igualmente, debido a que el fútbol soccer es el deporte tradicional más popular en Alemania, muchos se entretienen con videojuegos que se enfocan en esta disciplina. Este país cuenta con la liga de FIFA más importante del mundo, la World League Esports Bundesliga, la cual es transmitida también a través de canales televisivos. Gracias a la relevancia que ha ido ganando en estos años, equipos de fútbol tradicional han decidido invertir en equipos de fútbol electrónico (como el FC Schalke 04).

Según datos de Newzoo, se espera que, a finales de este año, el mercado germano genere más de 5 mil millones de dólares para las empresas de videojuegos, lo que lo ubicaría en el quinto lugar de países con más aportación a esta industria; esta cifra claramente se verá reflejada en la industria de los E-sports.

\section{España}

El caso español es muy interesante, ya que, de acuerdo con estimaciones de Newzoo, este país será el quinto país europeo que más aportará a la industria de los videojuegos en 2020, contribuyendo con poco más de 2 mil millones de dólares, lo que lo posiciona por debajo de Alemania, Reino Unido, Francia e Italia. No obstante, si se refiere al mundo de los E-sports, España lleva varios años trabajando para consolidarse como una de las potencias de la industria.

Guijarro Marín (2018) menciona que las tres mayores operadoras de telefonía en ese país (Movistar, Orange y Vodafone), han decidido apostar por los deportes electrónicos. Además, en su informe de 2017, Newzoo hace referencia a que España ocupa el duodécimo lugar en el ranking de audiencia de E-sports, con 2.6 millones de público.

Además, este país, es la cuna de una de las ligas más importantes de Europa y del hemisferio occidental en general, la Liga de Videojuegos Profesional o también conocida simplemente como LVP. En esta liga se realizan torneo de distintos E-sports, entre los cuales podemos encontrar a League of Legends, Counter Strike: Global Offensive y Free Fire. Según Nicola Cencherle, CEO de Riot Iberia, La Superliga Orange (de la LVP) es la liga nacional de League of Legends más fuerte de Europa (LVP, s.f). 


\section{Estados Unidos}

Estados Unidos, junto con Japón, son reconocidos como los lugares de nacimiento de los videojuegos (Wolf \& Iwatani, 2015). Aún hoy día, este país es el mayor desarrollador de títulos para la industria, lo que supone un gran atractivo para otras empresas que quieran adentrarse a este mundo.

De acuerdo con datos de Newzoo (2019), Estados Unidos fue el país que más ingresos generó para la industria de los videojuegos en 2019, contribuyendo con 36,900 millones de dólares, seguido por el mercado chino con 36,500 millones de dólares. Sin embargo, estimaciones del mismo Newzoo, posicionan al mercado norteamericano en segundo puesto para finales del presente año, dejándolo por debajo de China. De las 10 empresas de videojuegos que más ingresos percibieron en 2019, seis son estadounidenses. En conjunto, estas empresas facturaron un total de 11,877 millones de dólares, lo que equivale a casi un tercio del total de los ingresos que generaron los videojuegos en este país.

Las ligas de deportes electrónicos que han ido surgiendo en este país en los últimos años, poco a poco se vuelven relevantes y atractivas dentro de la escena competitiva para los jugadores profesionales, principalmente por el dinero que mueven. Henríquez (2020) entrevista a Hal Biagas, director ejecutivo de la North America LCS Players Association (NALCSPA), quien indica que el salario promedio de los jugadores de la LCS ha superado los 400,000 dólares. Esto significa que, en los últimos 3 años, el salario promedio de los jugadores ha aumentado casi un $400 \%$, pues en 2017 la media se situaba en 105,000 dólares y que el sueldo mensual oscila entre los 33 mil dólares para jugadores de entre las edades de 17 y 25 años en 2020.

Existen jugadores de más renombre como el caso de Huni o Impact (atletas de League of Legends), que cuentan con salarios que superan el millón de dólares. A esta suma, que ya en sí representa cifras enormes, se debe añadir el hecho de que los clubes, por regla general, deben cubrir las necesidades de sus jugadores, es decir, el hogar, la comida y todo tipo de gastos relacionados con su equipo de juego.

Como último punto, en este país ya existen universidades que ofrecen becas relacionadas con los E-sports, algunos casos son: Universidad Robert Morris, Universidad de Mount Union, Indiana Tech, Universidad de Maryville, Universidad de California, Universidad de Utah, entre otras. Las becas pueden variar entre cubrir el $50 \%$ de la matrícula hasta una beca completa de estudios. El principal e-sport por el que pueden otorgar estas ayudas es por League of Legends, deporte que se ha consolidado como la principal disputa entre universidades de aquel país.

\section{Caso Latinoamérica}

La escena profesional en la región latinoamericana ha generado bastantes expectativas para las marcas y para las empresas desarrolladoras en general, debido a los ingresos generados por la región en 2019; según datos de Newzoo, Latinoamérica contribuyó con 5,600 millones de dólares, lo que representó el $4 \%$ del total de las ganancias a nivel mundial. Este porcentaje es muy pequeño en comparación a las otras regiones, pero vale la pena mencionar que esta cifra representa un crecimiento del $11.1 \%$, lo que convierte a Latinoamérica en la región de más rápido crecimiento en el sector (Zapién, 2019).

Los cinco mercados que más aportaron a las ventas de videojuegos fueron: 1) México, con 1,800 millones de dólares, 2) Brasil, con 1,600 millones, 3) Argentina, con 495 millones, 4) Colombia, con 372 millones y 5) Chile, con 268 millones. Sin embargo, cuando se trata de E-sports, los brasileños representan el mercado más entusiasta, con 20 millones de espectadores, de los cuales 12 millones son ocasionales y el resto son verdaderos seguidores (Pérez-Tejada, 2019). Además, Brasil es el tercer país con la mayor afición a los E-sports en el mundo, sólo por debajo de Estados Unidos y China. 
Siguiendo a Pérez-Tejada (2019), los eventos más importantes en esta región son los siguientes:

- Argentina Game Show (Argentina). Evento en donde se hacen lanzamientos exclusivos de juegos, además de ser sede de varios torneos de E-sports.

- $\quad$ SP Gaming Tournament (Chile). Organiza eventos de League of Legends, PUBG, Overwatch y Hearthstone, en Chile.

- ROG E-sports Fest (México), organizado por la empresa de tecnología Asus.

- Gears Pro Circuit México (México), organizado por la empresa de videojuegos Epic Games.

- E-sports México (México). Se encarga de organizar torneos amateurs de Call of Duty, FIFA y League of Legends.

- Brasil Game Show (Brasil). Este evento es el más grande de todo Latinoamérica e incluye la final de la Brasil Game Cup, además de contar con la participación de celebridades internacionales de los Esports.

El mayor problema que presenta este territorio es el hecho de que sus jugadores, aunque estén interesados en competir dentro de la industria de los E-sports, no están dispuestos a gastar, por lo que para muchas desarrolladoras y patrocinadores, esto coloca una barrera entre ellos y el mercado, ya que no están seguros de si su inversión retornará (Agencia EFE, 2020).

Está claro que, como región, aún falta mucho para que Latinoamérica pueda posicionarse a la par de Estados Unidos, Europa o Asia, no obstante, es evidente que este mercado presenta un atractivo real para las empresas de videojuegos y para patrocinadores.

\section{Evolución de los E-sports en México}

La cultura pop mexicana siempre se ha visto influenciada por su vecino del norte; cuando una industria empieza a ganar fama del lado estadounidense, tarde o temprano llegará a México. Eso mismo pasó con la industria de los videojuegos cuando las primeras consolas fueron lanzadas en Estados Unidos, algunas empresas mexicanas, viendo el potencial enorme de negocio en ellas, decidieron traerlas al país, pero su precio era tan caro que sólo ciertas personas podían costearse ese juguete. Sin embargo, la demanda por las consolas continuó aumentando a tal grado que se empezaron a crear mercados de contrabando. A la fecha la mitad del consumo de videojuegos en esa época, en México, se hizo de forma ilegal (Cervera y Quesnel, 2014). En la actualidad, muchos usuarios de videojuegos ya no compran piratería, y esto se puede ver reflejado en las ventas de esta industria en el país, posicionándonos como el primer lugar de la región latinoamericana.

A pesar del mercado de contrabando que se había generado alrededor de las consolas, hubo muchos niños y jóvenes que aun así no pudieron adquirir este producto, por lo que, en los años 90s, con la llegada de las Arcades al país, el uso de éstas se convirtió en un hito dentro de la sociedad mexicana. Los lugares en donde se encontraban instaladas las "Maquinitas" (nombre que se le dio en México a las Arcades) sirvieron como puntos de encuentro para cientos de jóvenes que querían demostrar su superioridad, esto dio paso a las primeras competencias y torneos de los que se tiene registro. Cervera y Quesnel (2014) hacen una comparación entre cómo algunos consideran que el deporte nacional mexicano es la lucha libre, y el cómo los títulos que más se jugaron en las "maquinitas" de aquel momento fueron juegos de peleas como: Street Fighter, The King of Fighter, Marvel vs. Capcom, etc.; aún hoy día, México tiene de los mejores jugadores profesionales en esports de este género. Sin embargo, en 2015, el Gobierno mexicano prohibió el uso de las "maquinitas", argumentando que incitaban a los jóvenes y niños a entrar al mundo de los juegos de azar.

Otro negocio que creció de la mano con la llegada de las llamadas "maquinitas" fueron las revistas de videojuegos, en donde se daban a conocer novedades de esta industria, desde nuevos juegos hasta futuras consolas, 
pero lo que más llamaba la atención, eran las secciones en donde se hacían guías que ayudaban a los jugadores con un juego que fuera complicado de terminar. Las más conocidas de ese tiempo fueron: Club Nintendo, Atomix, Electronic Gaming Monthly, Official Xbox Magazine y Gamemaster. No obstante, cuando internet empezó a tomar relevancia y páginas como YouTube empezaron a surgir, la venta de revistas se desplomó, ya que toda la información que contenían podía encontrarse de manera gratuita en la web. Hoy día aún existen algunas de estas impresiones, pero sus ventas se deben en gran medida a la nostalgia que generan en los jugadores.

Según datos de The Competitive Intelligence Unit (CIU, 2020), en 2019, el valor del mercado mexicano fue de 32,262 millones de pesos, lo que representó un incremento del $19.3 \%$ con respecto al año anterior.

La cultura pop mexicana está fuertemente influenciada por la cultura pop estadounidense, por lo que, en 2014, cuando Estados Unidos empezó los trámites para poder aceptar a los deportes electrónicos como un deporte, en México también se buscó esto. Pero no fue sino hasta cuatro años más tarde, en 2018, cuando Ismael Silva, presidente de la Federación Mexicana de $E$ sports (FEMES), logró que la Comisión Nacional de Cultura Física y Deporte (CONADE) avalara la disciplina en México. Actualmente, la FEMES también cuenta con el aval de la World E-sports Consortium (WESCO), de la Panamerican E-sports Confederation (PAMESCO) y de la Confederación Centroamericana y del Caribe de E-sports (CONCECARES) (FEMES, 2020).

\section{Figura 4. Crecimiento del valor del mercado mexicano}

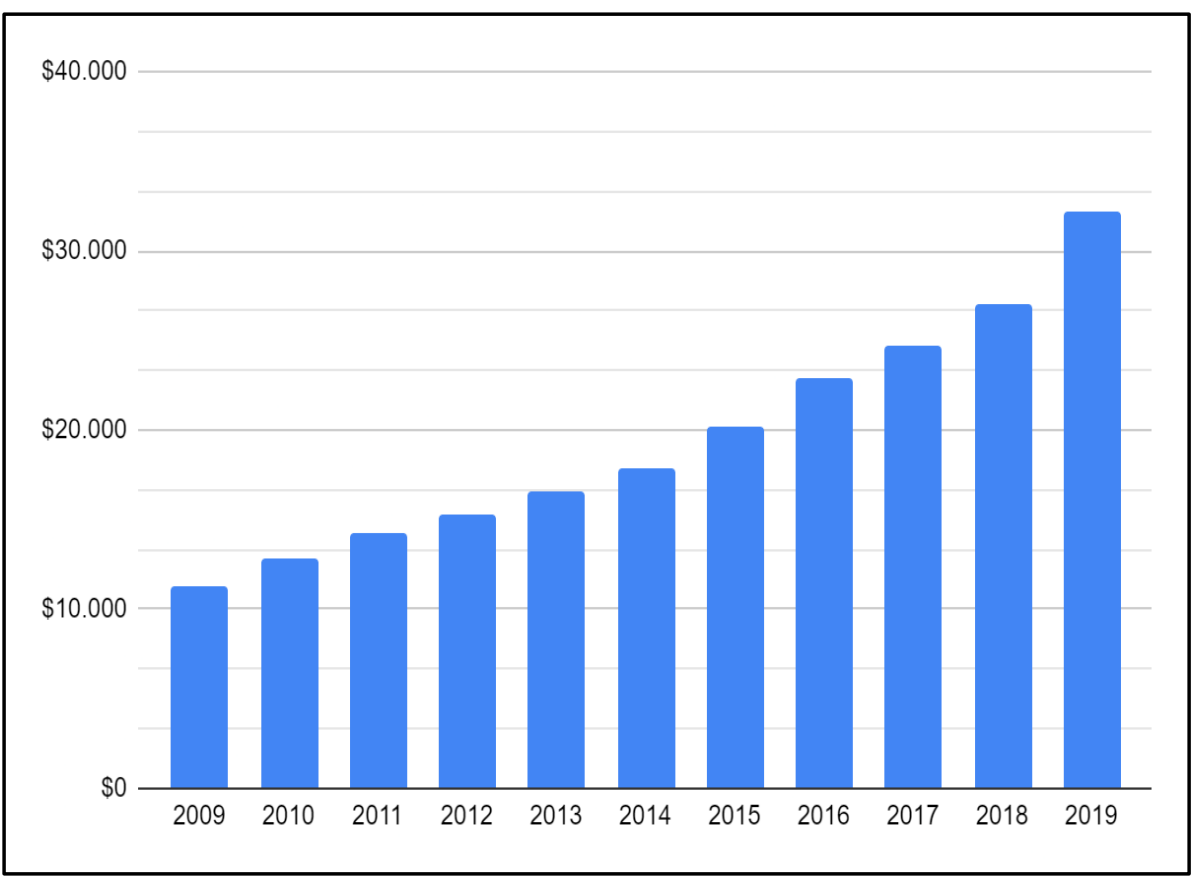

Fuente: elaboración propia con datos de The CIU, 2019.

\section{Escena profesional de los E-sports en México}

De acuerdo con datos de The CIU (2020), en
2019 en México se registraron un total de 72 millones de jugadores, los cuales participan de esta actividad mediante el uso de dispositivos móviles, consolas de videojuegos 
y computadoras. Esta cifra es $5.2 \%$ superior a la del 2018 y representa el $57 \%$ de la población total del país. Además, datos de la misma consultora, aseguran que, de esta cantidad, un $10,7 \%$ han participado en algún torneo nacional, el $13,4 \%$ ve streamings con esta temática, y el $9.9 \%$ ve torneos profesionales en línea.

\section{Empresas, patrocinios y publicidad}

Debido a las ganancias generadas por México para la industria de los videojuegos en los últimos años, éste se ha vuelto el principal protagonista de la región latinoamericana, posicionándose por encima de Brasil.

El crecimiento de los E-sports, además, ha atraído la atención de empresas como TV Azteca, la cual, a la fecha, ha invertido más de 5 millones de dólares, adquiriendo así a la empresa Black Ride Acquisition Corp, una productora de deportes electrónicos en Estados Unidos. Con esta adquisición, TV Azteca planea reproducir la estrategia de Fox Sports y ESPN de crear un canal de televisión en donde se transmitan deportes electrónicos las 24 horas del día (Pérez-Tejeda, 2019).

Cinemex, también decidió sumarse a esta industria, y en 2019 creó "Arena. The place to play", un concepto que en países asiáticos y europeos ya tiene tiempo, pero que en México es completamente nuevo. El complejo toma el concepto de los ciber cafés, pero lo lleva a una categoría superior, ya que cuenta con distintas consolas, pantallas de televisión con resolución $4 \mathrm{~K}$, PC gamers y red de internet con una velocidad mayor al promedio nacional, lo que permite que los jugadores puedan llegar sólo a pasar un buen momento de entretenimiento o que inclusive puedan llegar a entrenar (Zanella, 2019).

Otra empresa que ha visto el potencial del país es la desarrolladora de League of Legends, Riot Games. La cual, en unión con Cinemex y TV Azteca, inauguraron a principios del presente año, una sala exclusivamente para E-sports en la Ciudad de México (Juárez, 2020). La sala necesitó de una inversión de 2.5 millones de dólares y cuenta con capacidad para 100 personas. Se planea que en un principio éste funja como sede para los juegos inaugurales y de clausura de la liga mexicana de League of Legends, pero, según dijo Raúl Fernández, gerente general de Riot Games Latinoamérica, en un futuro cercano la sala también se podrá usar para llevar a cabo torneos de otros deportes.

Estas tres empresas no son las únicas invirtiendo; Televisa, otra de las grandes cadenas de medios en México, lanzó un canal de paga llamado Bit $M e$, en donde se transmiten programas de esta índole. Grupo HIR, constructora de la emblemática World Trade Center de Ciudad de México, también ha mencionado que tiene planes de construir estadios dedicados para los E-sports. Como ésas existen muchas otras que ven un mercado atractivo y que por lo tanto están decidiendo participar, lo que a mediano y largo plazo se verá en una escena competitiva mexicana mucho más estable y fortalecida.

\section{Premios y salarios de los jugadores}

A diferencia de la región asiática, de la europea o de su mismo vecino del norte, México aún se encuentra en una etapa temprana de las competencias de E-sports, ya que, como vimos en la sección anterior, las empresas apenas comienzan a invertir. Esto ha causado que los torneos celebrados a nivel nacional aún no puedan dar premios tan cuantiosos, lo que llega a desalentar a quienes tienen el sueño de dedicarse a esto.

Si se hace una comparación con Estados Unidos, en donde el salario promedio de un jugador es de 400,000 dólares anuales, México aún se encuentra muy por debajo, ya que, según datos de Gamelta (Liga de Esports para México y América Latina), el salario promedio de un jugador en el país ronda los 20 ó 30 mil pesos mensuales o lo que es igual, mil a mil quinientos dólares mensuales.

Este factor ha hecho que jugadores mexicanos prefieran firmar contratos con clubes internacionales antes que con nacionales. De los casos más conocidos son:

- Leonardo López Pérez. Jugador de Super Smash. Tras haber conseguido la victoria del campeonato mundial de este deporte, 
el club surcoreano T1 (de la compañía SK Telecom) decidió contratarlo.

- Daniel Velasco. Jugador de Gears of Wars. Ganador del Gears Vegas 2018 y actual miembro del equipo estadounidense Ghost Gaming.

- David Lucio. Jugador de FIFA. Campeón nacional de 2017 y mundialista de este deporte en 2018. Fue contratado por el equipo francés de Nantes.

- Francisco Jara. Jugador de League of Legends. Actual campeón de la liga latinoamericana de esta disciplina con el equipo argentino Rainbow 7.

El panorama actual se ve más prometedor que hace unos años, por lo que, esta fuga de talentos puede ser que un tiempo no tan prolongado, se logre evitar, dado que en México existen jugadores con las capacidades suficientes para enfrentar a deportistas de cualquier parte del mundo.

\section{Oportunidades para jóvenes mexicanos}

Como se puede apreciar a lo largo de este trabajo de investigación, año con año la industria de los E-sports crece constantemente y con ella las oportunidades para que cientos de jóvenes mexicanos puedan prosperar. No debe malentenderse este punto, ya que cuando se menciona oportunidad, con esto no se refiere únicamente al trabajo de jugador profesional, sino a toda la rama de ocupaciones que se generarán gracias a esta industria, desde coach o asesor de jóvenes que quieran convertirse en profesionales, hasta el hecho tan simple de montar un canal en cualquiera de las plataformas de streaming que se mencionaron.

Además, existe otra forma en la que los $E$ sports pueden traducirse como algo que permita a los jóvenes prosperar, y es por medio de becas deportivas. Así como se mencionaba en la parte del caso de Estados Unidos, en México ya hay universidades que brindan este tipo de becas a jóvenes que tienen talento en los deportes electrónicos. El pionero fue el Tecnológico de Monterrey, campus Guadalajara, que desde 2018 facilita esta beca para que cualquier joven con talento pueda ingresar a su universidad, ya que ésta cubre el costo completo de matrícula e inscripción; posteriormente, en 2019, se unieron a esta iniciativa la Universidad Iberoamericana y la Universidad Anáhuac, y más recientemente universidades públicas como la UNAM y el Instituto Politécnico Nacional (Sierra, 2020; Castañares, 2017; Chinonso, 2020).

\section{MÉTODO}

Esta investigación es de diseño documental con enfoque exploratorio y diseño no experimental. Se consultaron diversas fuentes de información, donde se recopilaron cifras, datos, estimaciones y otras variables numéricas, a través de plataformas estadísticas y documentos secundarios.

\section{CONCLUSIONES}

Si bien México ha sido uno de los grandes protagonistas dentro de la industria de $\operatorname{los} E$ sports en la región latinoamericana, aún está lejos de competir contra las grandes regiones como los son la europea, la asiática o la estadounidense. Sin embargo, según lo que se ha visto en los últimos años, nuestro país se encuentra en un proceso de transición por medio del cual puede llegar a un nivel de infraestructura tecnológica avanzado, con lo que afianzará un ambiente propicio para el crecimiento de las competencias nacionales de deportes electrónicos.

Los E-sports, tal y como lo afirma Felizzola (2019), tienen el potencial de fomentar la convivencia humana e inclusive de generar capacidades a través del aprendizaje autónomo, lo que genera nuevas oportunidades.

Los últimos años 2020 y 2021 han sido fuertemente afectados por la pandemia del Covid-19, lo que ha presentado obstáculos para el desarrollo de la economía mundial, por lo que muchos sectores productivos han tenido que suspender o cerrar actividades, y, según analistas del medio, el 2021, presenta un panorama bastante desfavorable para el desarrollo empresarial.

Los E-sports son una alternativa y juegan 
un rol importante, ya que cualquier persona puede abrir un canal de Twitch o de Facebook Gaming, y empezar a streamear y con eso, existe la posibilidad de que se tenga un ingreso por medio de las suscripciones de usuarios o por medio de los anuncios integrados de la misma plataforma. Hacer esto no requiere de mucho dinero, ya que sólo se necesita de una computadora que cumpla con las especificaciones técnicas del E-sport en cuestión, una cámara de video y una conexión a internet.

En este sentido, la creatividad y emprendimiento de la generación millenial o centennial puede dirigir las afinidades actuales hacia este tipo de industrias, donde incluso, la forma de aprender se ha hecho a través de la gamificación o el uso de plataformas lúdicas que, han potenciado el aprendizaje de inteligencias virtuales que detonan las inteligencias múltiples en las personas. "Las tendencias e inquietudes actuales exigen cada día más una respuesta a las generaciones de jóvenes que necesitan encontrar respuesta en el contexto educativo a sus expectaciones tecnológicas y necesidades más inmediatas". Ortiz-Colón, Jordán y Agredal (2018, p.2). Esto incide en los desafíos actuales para desarrollar espacios empresariales innovadores, que consideren los cambios tecnológicos, a partir del diseño de estas propuestas de sofisticación comercial que este tiempo demanda, que indudablemente, serán lideradas por estas jóvenes generaciones. 


\section{REFERENCIAS}

Academia E-sports. (s.f.). Descubre cuáles son los E-sports más jugados del momento. Academia E-sports. En: https://www.academiaesports.com/esports-mas-jugados/

Antevenio. (2019). Analizamos la audiencia de los E-sports: su edad, sus gustos, lo que consumen. Antevenio. En: https://www.antevenio.com/blog/2019/05/analizamos-la-audiencia-de-losesports/\#: :text=De\%20esta\%20forma\%2C\%20el\%20target,presencia\%20tambi\%C3\%A9n $\% 20 \mathrm{en} \% 20 \mathrm{este} \% 20$ sector.

Banks, T. (2017). Generaciones de Videoconsolas: Historia, evolución y las más vendidas. Tecnobreak. En: https://www.eleconomista.com.mx/opinion/La-industria-de-losvideojuegos-en-Mexico-20180703-0135.html

Belli, S. y López Raventós, C. (2008). Breve historia de los videojuegos. Athenea Digital. Revista de Pensamiento e Investigación Social, (14),159-179. En: https://www.redalyc.org/articulo.oa?id=537/53701409

Castañares, I. (2017). ¿Cuánto gana un 'gamer' mexicano? El Financiero. En: https://www.elfinanciero.com.mx/empresas/cuanto-gana-un-gamer-mexicano

Cervera, H. y Quesnel, J. (2014). Video games around the world Mexico. En: https://xgamebrainx.wordpress.com/2013/09/18/video-games-around-the-world-mexico/

Chanson, R. (2017). E-sports. Todo lo que necesitas saber de League of Legends al FIFA. Planeta.

Chinonso, G. (2020). E-sports scholarship 2020 para estudiantes internacionales [Actualizado]. World Scholarship Forum. En: https://worldscholarshipforum.com/es/esports-scholarship/

Cristòfol, F. J., Martínez-Ruiz, Álvaro, Román-Navas, I., \& Cristófol-Rodríguez, C. (2020). Evolución de las estrategias de patrocinio en los E-sports en España: 2013-2021. Ámbitos. Revista Internacional de Comunicación, (48), 188-204. En: https://doi.org/10.12795/Ambitos.2020.i48.10

Dal Yong J. (2010). Korea's Online Gaming Empire. The MIT Press. En: https://search-ebscohostcom.e-

revistas.ugto.mx/login.aspx?direct=true $\& \mathrm{db}=\mathrm{e} 000 \mathrm{xww} \& \mathrm{AN}=324704 \&$ lang $=$ es $\&$ site $=$ ehost$\underline{\text { live }}$

Del Río González, A. (2018). La evolución de los E-sports. Universidad de Sevilla. En: https://idus.us.es/bitstream/handle/11441/78511/TFG\%20CAV\%20$\% 20 \mathrm{Alba} \% 20 \mathrm{del} \% 20 \mathrm{R} \% \mathrm{c} 3 \%$ ado\%20Gonz\%c3\%a1lez.pdf?sequence=1\&isAllowed =y

EFE Agencia. (2020). La pandemia acelera el "inevitable" auge de los E-sports en Latinoamérica. Agencia EFE. En: https://www.efe.com/efe/america/tecnologia/la-pandemia-acelera-elinevitable-auge-de-los-esports-en-latinoamerica/20000036-4361239

Felizzola, O. (2019). El deporte virtual y la realidad de la gestión humana. Debates IESA, 24(3), pp.13-14.

Galván, M. (2020). Consumo de videojuegos alcanza su máximo histórico en Estados Unidos. Level Up. En: https://www.levelup.com/noticias/599244/Consumo-de-videojuegos-alcanzasu-maximo-historico-en-Estados-Unidos

García Callealta, D. (2016). El impacto social de League of Legends en Corea del Sur. En: https://gredos.usal.es/bitstream/handle/10366/132850/TFM_GarciaCallealta_Impacto.pdf?seq uence $=1 \&$ isAllowed $=\mathrm{y}$

Garza, J. (2019). China reconoce el "gaming" como actividad laboral profesional. La República. En: https://www.larepublica.net/noticia/china-reconoce-el-gaming-como-actividad-laboralprofesional

Gimeno, B. (2019). ¿Qué requisitos debe cumplir un videojuego para ser un eSport? Marca. En: https://www.marca.com/esports/2019/05/31/5cf12473ca474178598b4587.html

Gómez, D. (2020). Los E-sports, cada vez más cerca del deporte de élite: patrocinios, entrenamiento y profesionalización. Menzig. En: https://www.menzig.es/a/esportsprofesionalizacion-marcas-patrocinios/

Guijarro Marín, A. (2018). Análisis cuantitativo sobre los E-sports. Universidad de Alicante. En: 
https://rua.ua.es/dspace/bitstream/10045/85807/1/TFG-Alvaro-Guijarro-Marin.pdf

Guiñón, A. (2017). Los clubes de fútbol europeos con presencia en los E-sports. En: https://as.com/E-sports/2017/09/09/mas E-sports/1504974850 250189.html

Henríquez, M. (28 de mayo de 2020). Sueldo promedio de jugador de la LCS supera los 400 mil dólares al año. En: https://es-us.finanzas.yahoo.com/noticias/sueldo-promedio-jugador-lcssupera-134000692.html

IMS. (2019). El fenómeno E-sports, el nuevo clásico. IMS. En: https://www.imscorporate.com/elfenomeno-esports/

Ivory, J. D. (2016). A brief history of Video Games.Taylor \& Francis. Routledge. ISBN: 978-1138-83160-5.

https://books.google.es/books?id=YJzCgAAQBAJ\&lpg=PA1\&dq=a\%20brief\%20history\%20of\%20video\%20games\&lr\&hl=es

$\& p g=\mathrm{PP} 1 \# \mathrm{v}=$ onepage $\& \mathrm{q} \& \mathrm{f}=$ false

Juárez, A. \& Castañares, I. (S/F). México, la tierra digital prometida de los E-sports. El CEO. En: https://elceo.com/tecnologia/mexico-la-tierra-digital-prometida-de-los-E-sports/

Juárez, A. (2020). TV Azteca, Cinemex y Riot games inauguran su estadio de E-sports en CDMX. El CEO. En: https://elceo.com/tecnologia/tv-azteca-cinemex-y-riot-games-inauguran-suestadio-de-esports-en-cdmx/

Kowert, R. \& Quandt, T. (2016). The video game debate: Unravelling the Physical. Social and Psychological effects of digital games. Routledge. EEUU.

Little Loans. (2020). The gamer rich list. Little loans. En: https://www.little-loans.com/gamers-rich$\underline{\text { list }}$

LVP. (2020). ¿Quiénes somos? Liga de Videojuegos Profesional. LVP. En: https://lvp.global/quienes-somos/

M. M. (2020). 400,000 dólares por jugar profesionalmente a League of Legends. Marca. En: https://www.marca.com/esports/league-oflegends/2020/06/06/5edbabf9ca4741d36f8b45fb.html

Maeso, G. (2020). Los E-sports que más dinero repartieron en 2019. Red Bull. En: https://www.redbull.com/es-es/esports-top-10-juegos-repartieron-mas-dinero-premios-2019

Mark J. P. W. (2015). Video Games Around the World. The MIT Press. En: https://searchebscohost-com.e-

revistas.ugto.mx/login.aspx?direct=true $\& \mathrm{db}=\mathrm{e} 000 \mathrm{xww} \& \mathrm{AN}=988342 \&$ lang=es $\&$ site=ehost$\underline{\text { live }}$

Mateo, J.A. (2019). Entre un negocio en auge y el temprano historial de amaños: las apuestas llegaron a los E-sports. Xataka. En: https://esports.xataka.com/analisis/apuestas-mundoesports-negocio-13-000-millones-euros-al-ano

Merisation (14 de noviembre de 2020). Los 60 años de SEGA: un recorrido lleno de historia e incertidumbre. $2020 . \quad$ En: https://as.com/meristation/2020/11/14/reportajes/1605344848_171306.html

Newzoo. (2019). Top 10 countries/markets by game revenues. Newzoo. En: https://newzoo.com/insights/rankings/top-10-countries-by-game-revenues/

Olivera Oceguera, Y. (2018). La industria de los videojuegos en México. El Economista. https://www.eleconomista.com.mx/opinion/La-industria-de-los-videojuegos-en-Mexico20180703-0135.html

Ortiz-Colón, Ana-M., Jordán, Juan, \& Agredal, Míriam. (2018). Gamificación en educación: una panorámica sobre el estado de la cuestión. Educação e Pesquisa, 44, e173773. Epub. En: https://doi.org/10.1590/s1678-4634201844173773

Pannekeet, J. (2018). Newzoo: Global E-sports economy will reach $\$ 905.6$ million in 2018 as brand investment grows by $48 \%$. Newzoo. En: https://newzoo.com/insights/articles/newzoo-globalesports-economy-will-reach-905-6-million-2018-brand-investment-grows-48/

Parry, J. (2018). E-sports are Not Sports. Sport, Ethics and Philosophy, 13(1). pp.1-16. En: https://10.1080/17511321.2018.1489419 
Peres, I. (2019). El valor de la industria de los videojuegos en 2019. Forbes México. En: https://www.forbes.com.mx/el-valor-de-la-industria-de-los-videojuegos-en2019/\#: :text=En\%20su\%20reporte\%20anual\%202019, dispositivos\%20m\%C3\%B3viles\%2 C\%20PC\%20y\%20consolas.

Pérez, J. (2018). LoL Park, el asombroso estadio de Riot Games en Corea. El desmarque. En: https://esports.eldesmarque.com/league-of-legends/lol-park-el-asombroso-estadio-de-riotgames-en-corea-54404

Pérez-Tejada, J.P. (2019). La profesionalización de los eSports en Latinoamérica. New Tech Mag.Net. En: http://newtechmag.net/es/2019/06/30/la-profesionalizacion-de-los-esports-enlatinoamerica/

Reymann-Schneider, K. (22 de agosto de 2018). Gamescom Alemana en los videojuegos. En: https://www.dw.com/es/gamescom-alemania-en-los-videojuegos/a-45187098

Riquelme, R. (2020). ¿Qué son los eSports? Todo sobre el fenómeno de los deportes electrónicos. El Economista. En: https://www.eleconomista.com.mx/tecnologia/que-son-los-esports20200207-0058.html

Romero, D. (2019). Jugadores de fútbol que están metidos de lleno en los eSports. Marca. En: https://www.marca.com/esports/2019/08/16/5d56b9d9e2704e8f548b4590.html

Rosas, V. (2020). FIFA 21 conquista Estados Unidos; fue el juego más vendido de Octubre. Level Up. En: https://www.levelup.com/noticias/599223/FIFA-21-conquista-Estados-Unidos-fueel-juego-mas-vendido-de-octubre

Sierra, L. (2020). Universidades privadas de México impulsan a la práctica de los eSports. Diez. En: https://www.diez.hn/esports/1369487-441/universidades-mexico-impulsan-esports-league-oflegends

The Competitive Intelligence Unit [The CIU]. (2020). \#DíaDelGamer2020: Industria de videojuegos en México. The CIU. En: https://www.theciu.com/publicaciones2/2020/8/28/dadelgamer2020-industria-de-videojuegos-en-mxico

Twitch Tracker. (2020). Twitch Statistics \& Charts. TwitchTracker. En: https://twitchtracker.com/statistics

Wijman, T. (2019). The global games market will generate $\$ 152.1$ billion in 2019 as the U.S. overtakes China as the biggest market. Newzoo. En: https://newzoo.com/insights/articles/theglobal-games-market-will-generate-152-1-billion-in-2019-as-the-u-s-overtakes-china-as-thebiggest-market/

Wolf, M. \& Iwatani, T. (2015). Video Games around the world. Routledge

Xinhua News. (2020). Xinhua News. En: http://spanish.xinhuanet.com

Young Hoon, K., Nauright, J. \& Suveatwatanakul, C. (2020). The rise of E-sports and potential for Post-COVID continued growth. Sport in Society, (23)11, pp.1861-1871. En: https://doi.org/10.1080/17430437.2020.1819695

Zanella, K. (2019). Arena: la nueva sala de videojuegos en CDMX ;con 200 juegos! Dónde IR. En: https://www.dondeir.com/ciudad/arena-la-nueva-sala-videojuegos-en-cdmx/2017/12/

Zapién, A. (2019). México lidera el mercado de Gaming en Latam. MDC. En: https://www.mdcdatacenters.com/es/company/blog/mexico-leads-the-gaming-market-inlatin-america/

Zaragoza, A. (2017). El merchandising en los E-sports. Movistar E-sports. En: https://esports.as.com/industria/merchandisingesports 0 1079592040.html\#: :text=El\%20merchandising\%20es\%20una\%20de,la\%20comp ra\%20de1\%20producto\%20propio 